\title{
Correlation between air-sea heat fluxes over the Aegean Sea and the total precipitable water over Europe and North Africa
}

\author{
V. P. Papadopoulos ${ }^{1}$, A. Bartzokas ${ }^{2}$, T. Chronis ${ }^{1}$, S. Ruiz ${ }^{3}$, N. Zarokanellos ${ }^{1}$, and G. Ferentinos ${ }^{4}$ \\ ${ }^{1}$ Hellenic Centre for Marine Research, Anavissos, Greece \\ ${ }^{2}$ Department of Physics, University of Ioannina, Greece \\ ${ }^{3}$ IMEDEA (CSIC-UIB), Mallorca, Spain \\ ${ }^{4}$ Department of Geology, University of Patras, Greece
}

Received: 23 October 2010 - Revised: 18 February 2011 - Accepted: 21 March 2011 - Published: 31 March 2011

\begin{abstract}
The relation between the air-sea heat fluxes in the Aegean Sea and the total precipitable water (TPW) over Europe and North Africa is investigated. An one-point linear correlation between the components of surface heat exchange and TPW is employed. During winter and for the shortwave radiation, a dipole of opposite correlation (see-saw teleconnection), is observed between the northeast Europe and the East Mediterranean Sea. This pattern is inverted for the longwave radiation and especially during the summer is limited to a strong positive south pole. Both spatial correlation patterns underline the influence of cloudiness during the winter season and the specific humidity during summer on the radiative fluxes behavior. Regarding the turbulent air-sea heat flux components - latent and sensible heat - the correlation pattern is enhanced. The winter pattern exhibits positive correlation over Europe with the highest values $(r>0.75)$ over the Balkan Peninsula. The identified correlation patterns, although they remain dominant, weaken during the summer. The herein findings suggest that the stronger relation between the TPW and the turbulent fluxes is regulated by the wind regime.
\end{abstract}

\section{Introduction}

Air-sea heat fluxes are critical for the climate regulation and affect a number of significant processes for both ocean and atmosphere from the global to the local scale. They govern the oceanic and atmospheric circulation and they are important inputs in the numerical weather prediction (NWP) models.

The total precipitable water (TPW) is an atmospheric parameter related to the ocean-atmosphere energy balance. The TPW is highly correlated with cloud formation and precipitation and is mostly used in the precipitation forecasting/nowcasting. Moreover, it exhibits a positive feedback to the global warming as higher water vapor amount in the atmospheric column increases the fraction of the infrared radiation which is trapped within the atmosphere (IPCC, 2001).

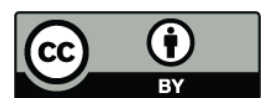

Correspondence to: V. P. Papadopoulos (vassilis@ath.hcmr.gr)
The Aegean Sea is an important area where intense air-sea interactions lead to the formation of intermediate and deep waters. The latter affect the thermohaline circulation of the Eastern Mediterranean Sea (Roether et al., 1996; Nittis et al., 2003). This vital process for the renewal and oxygenation of near bottom water layers is directly related to the surface heat exchange regime. The study at hand examines the relationship between the air-sea heat fluxes over the Aegean Sea and the spatial distribution of the TPW over the Northeast Atlantic, Europe and North Africa. The two parameters are regulated by common factors like the sea level pressure (SLP) variability and the wind field. Furthermore, cloudiness and specific humidity, both strongly linked to TPW, modulate the radiative components (shortwave and longwave radiation, SW and LW). Conversely, evaporation releases latent heat $(\mathrm{LH})$ and transfers water from ocean to atmosphere and the turbulent fluxes affect the precipitation regime (Lolis et al., 2004). Therefore, the co-variability of the TPW and the surface fluxes is expectedly of high interest for the climatology of the Aegean Sea and the Eastern Mediterranean. 


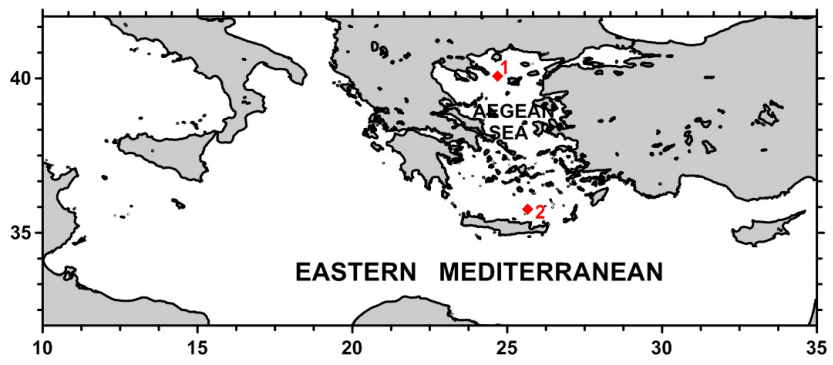

Figure 1. Location of the two sites in the North (1) and South (2) Aegean Sea at which the surface heat exchanges are correlated with the field of TPW.

\section{Data and methodology}

Monthly mean air-sea heat fluxes at two sites in the North and the South Aegean Sea (Fig. 1) originate from two different datasets. The special Mediterranean HIPOCAS dataset (1958-2001, Sotillo et al., 2005; Ratsimandresy et al., 2008), provided by Puertos del Estado (Spain), is employed for the radiative, whereas the global OAFlux (1958-2006, Yu and Weller, 2007) for the turbulent fluxes (latent and sensible heat, $\mathrm{LH}$ and $\mathrm{SH})$. The two datasets are qualified as statistically robust for the Aegean Sea region after a comparison with an observational dataset (Papadopoulos et al., 2010). Note that we use the oceanographic convention for the heat flux according which positive values represent heat gain by the sea.

Monthly mean TPW values are retrieved from the ERA-40 reanalysis dataset (Uppala et al., 2005) and cover an area extending from $15 \mathrm{~W}$ to $45 \mathrm{E}$ and from $25 \mathrm{~N}$ to $70 \mathrm{~N}$ at a $2.5 \mathrm{de}-$ grees resolution square grid. In order to examine the relation between the surface heat exchanges and the TPW field, we apply one-point linear correlation between the air-sea heat flux anomalies and the TPW anomalies at each of the 21 by 19 total grid points. This correlation is computed for both Aegean Sea sites and separately for the cold (NovemberMarch) and the warm (May-September) season of the year. A composite correlation map for the North and South Aegean is presented for each period of the year and for each flux component of the air-sea heat flux. Every composite correlation map is produced by averaging the correlation maps for the North and South Aegean Sea. Only the statistically significant $(r)$ values at a confidence level of $95 \%$ are accounted for. Especially for the SH flux, we present only the winter correlation. Usually, during summer $\mathrm{SH}$ displays positive values but often negative monthly mean values are also observed. The sign of $\mathrm{SH}$ is regulated by the difference between the air and the sea temperature, whereas the wind speed determines its magnitude. For this reason, including positive and negative $\mathrm{SH}$ values misrepresents the evaluation of the calculated correlation coefficients.

\section{Results and discussion}

Figure 2 illustrates the correlation maps for the cold and the warm season of the year and for the radiative and turbulent (LH only) components. During winter, SW and TPW exhibit a dipole of opposite correlation (see-saw teleconnection, Fig. 2a), between the north Europe and East Mediterranean Sea. Since low SW values go along with high LW, this pattern is inverted for the LW (Fig. 2c). SW and LW are inversely influenced by the cloud fraction which in turn is strongly correlated with TPW. Overcast conditions with high TPW values implies lower SW values and higher LW. Both winter correlation patterns underline that an increase of TPW over northern Europe and the simultaneous decrease over eastern Mediterranean imply a decrease of total cloud coverage over the Aegean Sea and vice-versa. Composite SLP maps during the lowest and highest SW values also support the observed see-saw pattern. The lowest values of SW over the South Aegean are associated with low SLP over central Mediterranean and high SLP over central and eastern Europe. This SLP pattern favors higher values of TPW over the Aegean Sea and lower over central and eastern Europe (Fig. 3a). On the contrary, during the highest winter $\mathrm{SW}$ values high pressures prevail over the greater part of Europe and over the Balkan Peninsula (Fig. 3b). Accordingly to this pattern, west winds cause higher TPW values over north Europe, whereas dry northerlies reduce the cloud fraction and increase SW values over the Aegean Sea. During summer only the negative south pole is observed for the SW (Fig. 2b) and a stronger (in comparison to the winter) positive south pole for the LW (Fig. 2d). The summer cloud fraction is systematically low and the higher specific humidity takes the role of the cloudiness creating a physical trap for the LW emitted by the sea surface. Both, cloud fraction and specific humidity, reduce the heat loss by the LW (see the relevant bulk formula, e.g. Bignami et al., 1995). As higher temperatures favor higher specific humidity values this provides an adequate explanation of the TPW contribution to the positive feedback of the greenhouse warming.

Regarding the turbulent air-sea heat flux components, a different correlation pattern is shown (Fig. 2e and f). These exhibit a strong positive correlation $(r>0.75)$ over the Balkan Peninsula indicating TPW decrease (increase) when turbulent fluxes in Aegean Sea increase (decrease). The flux anomalies decrease when the heat losses increase as LH and $\mathrm{SH}$ are both negative during winter. This pattern is also consistent with the SLP composites during the lowest and highest LH values (Fig. 3c and d). High SLP over central Europe favors the strong cold and dry northerlies dominating over the Aegean Sea throughout the year (Chronis et al., 2010) and increases the turbulent heat loss. At the same time, the lower TPW over the continental Europe is attributed to the prevailing high barometric pressures. These high pressures covering the greater part of continental Europe create the necessary pressure gradient for the dominant northerlies over the 

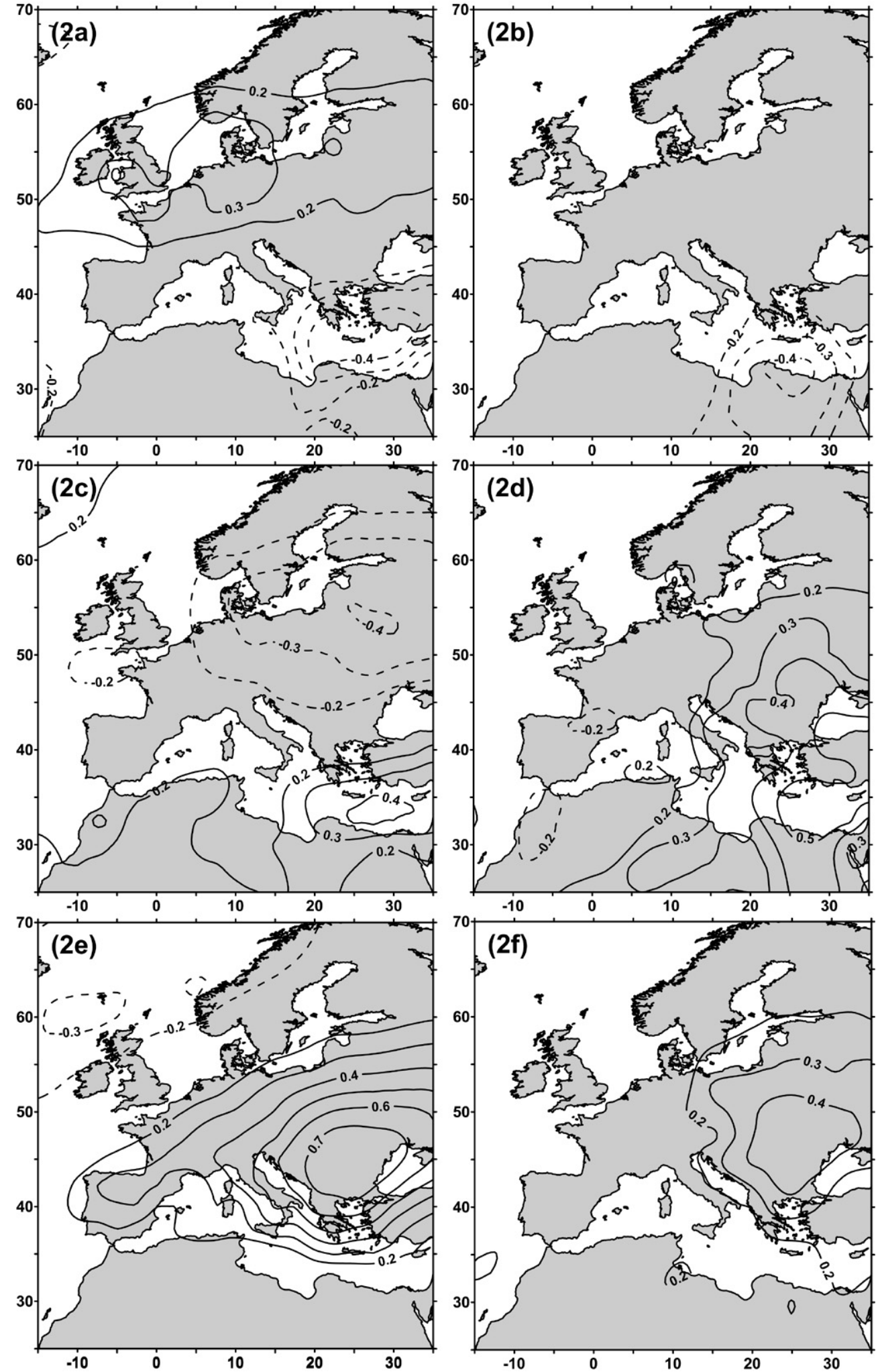

Figure 2. Correlation maps between TPW and (a) shortwave radiation during winter, (b) shortwave radiation during summer, (c) longwave radiation during winter, (d) longwave radiation during summer, (e) latent heat during winter and (f) latent heat during summer. Dashed lines indicate negative correlation. 

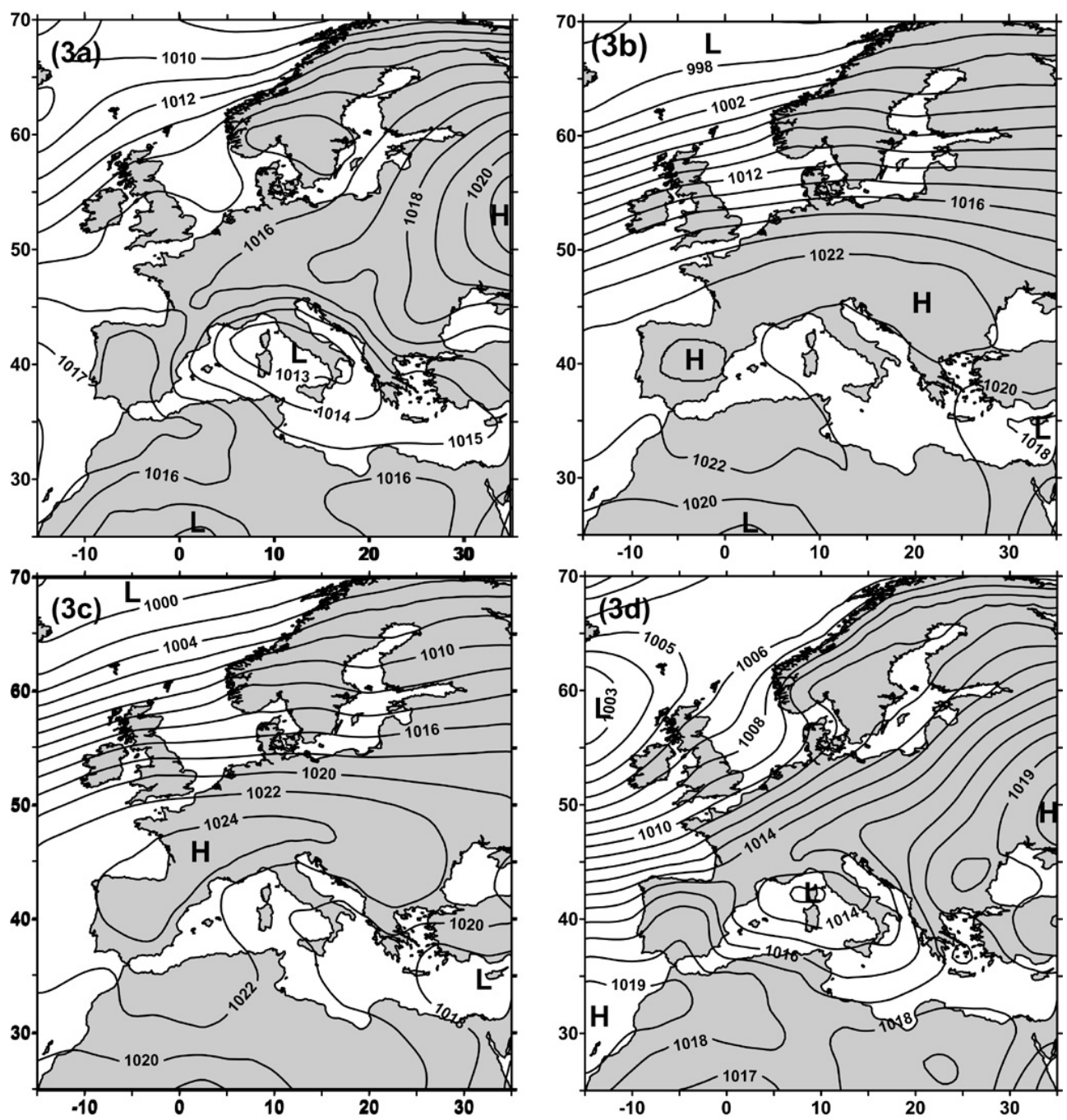

Figure 3. Composite SLP (in hPa) distribution for: (a) the lowermost 10\% extreme values of SW occurring within the period 1958-2001 in South Aegean during winter, (b) the uppermost 10\% SW values, (c) the lowermost 10\% LH values and (d) the uppermost $10 \%$ LH values.

Aegean. The presence of the Cyprus Low during the winter and the thermal Low of Northwest Asia during the summer is also synergistic in enhancing the northerlies (Flocas et al., 2010). The identified correlation pattern for the latent heat weakens during summer although it still remains prominent (Fig. 2f).

\section{Conclusions}

The correlation between the components of the air-sea heat fluxes over the Aegean Sea and the TPW over Europe and North Africa reveals the following key features:

- A moderate correlation is observed between the radiative fluxes and the TPW which are naturally related to cloudiness during winter and specific humidity during summer.
- The longwave radiation is the only flux component that exhibits stronger correlation with TPW during summer than winter.

- Higher specific humidity during summer traps a higher fraction of the longwave radiation indicating the role of TPW in positive feedback of the global warming.

- The correlation between turbulent fluxes and TPW $(r>$ $0.75)$ is stronger than the correlation between radiative fluxes and TPW since turbulent fluxes and TPW are regulated by the same parameters.

- The correlation pattern for the turbulent fluxes is affected by the presence of high pressures centers over the continental Europe which in combination with the Cyprus Low during winter and the thermal NW Asia Low during summer generate the cold and dry northerlies over the Aegean Sea. 
In summary, the air-sea heat fluxes in the Aegean Sea and the field of TPW over Europe and North Africa are mainly affected by the wind regime which in turn is regulated by the large scale atmospheric circulation. The spatial and temporal variability of both variables is very important not only for the marine environment but for the whole climatic regime of the Eastern Mediterranean region.

Edited by: B. Lalic

Reviewed by: S. Gualdi and two other anonymous referees

\section{SC nat $\$$ The publication of this article is sponsored by the Swiss Academy of Sciences.}

\section{References}

Bignami, F., Marullo, S., Santoleri, R., and Schiano M. E.: Longwave radiation budget in the Mediterranean Sea, J. Geophys. Res., 100(C2), 2501-2514, 1995.

Chronis, T., Papadopoulos, V., and Nikolopoulos, E.: QuickSCATob servations of extreme wind events over the Mediterranean and Black Seas during 2000-2008, Int. J. Climatol., doi:10.1002/joc.2213, 2010.

Flocas, H. A., Simmonds, I., Kouroutzoglou, J., Keay, K., Hatzaki, M., Bricolas, V., and Asimakopoulos, D.: On cyclonic tracks over the Eastern Mediterrranean, J. Climate, 23, 5243-5257, 2010.

Lolis, C. J., Bartzokas, A., and Katsoulis, B. D.: Relation between sensible and latent heat fluxes in the Mediterranean and precipitation in the Greek area during winter, Int. J. Climatol., 24, 18031816, 2004.
IPCC: Climate Change 2001: The Scientific Basis, Cambridge University Press, 881 pp., 2001.

Nittis, K., Lascaratos, A., and Theocharis, A.: Dense water formation in the Aegean Sea: numerical simulations during the Eastern Mediterranean Transient, J. Geophys. Res., 108(C9), 8120, doi:10.1029/2002JC001352, 2003.

Papadopoulos, V. P., Chronis, T. G., Ruiz, S., Tragou, E., Josey, S., and Ferentinos, G.: Air-sea heat fluxes estimation in the Aegean Sea (Eastern Mediterranean), Rapp. Comm. Int. Mer Medit., 39, p. 156, 2010.

Ratsimandresy, A. W., Sotilo, M. G., Carretero, J. C., Alvarez, E., and Hajji, H.: A 44-year-high-resoloution ocean and atmospheric hindcast for the Mediterraneaan Basin developed within the HIPOCAS Project, Coast. Eng., 55, 827-842, 2008.

Roether, W., Manca, B., Klein, B., Bregant, B., Georgopoulos, D., Beitzel, V., Kovacevic, V., and Luchetta, A.: Recent changes in eastern Mediterranean deep waters, Science, 271, 333-335, 1996.

Sotillo, M. G., Ratsimandresy, A. W., Carretero, J. C., Bentamy, A., Valero, F., and Gonzaìlez-Rouco, F.: A high-resolution 44-year atmospheric hindcast for the Mediterranean Basin: contribution to the regional improvement of global reanalysis, Clim. Dyn., 25, 219-236, 2005.

Uppala, M. and 45 co-authors: The ERA-40 re-analysis, Q. J. Roy. Meteor. Soc., 131, 612, 2961-3012, 2005.

Yu, L. and Weller, R. A.: Objectively analyzed air-sea heat fluxes for the global ice-free oceans (1981-2005), B. Am. Meteorol. Soc., 88, 4, 527-539, 2007. 